\title{
Benign Respiratory Tract Neoplasm
}

National Cancer Institute

\section{Source}

National Cancer Institute. Benign Respiratory Tract Neoplasm. NCI Thesaurus. Code C8531.

A non-metastasizing neoplasm arising from the lung parenchyma, bronchial tree, or trachea. Representative examples include lung hamartoma, lung papilloma, and tracheal leiomyoma. 